\title{
Treatment effects of reverse total shoulder arthroplasty - a simple method to measure outcomes at 6, 12, 24 and 60 months for each patient
}

\author{
Joerg Huber ${ }^{1^{*}}$ (D) Ulrich Irlenbusch², Max J. Kääb ${ }^{3}$, Falk Reuther ${ }^{4}$, Georges Kohut ${ }^{5}$ and Andy Judge $e^{6,7,8}$
}

\begin{abstract}
Background: Although shoulder arthroplasty is less common than knee or hip arthroplasty, the number of procedures being performed is increasing rapidly. The treatment effect is a simple method to measure outcome of joint replacement. The method was applied to measure results of total hip/knee arthroplasty but not yet for shoulder arthroplasty.

Methods: Included were patients with unilateral cuff arthropathy (Hamada grades $>=2$ ) treated with reversed total shoulder arthroplasty (RSA) in this prospective multicenter study. The patients were assessed with the ASES questionnaire. The treatment effects (TE) was calculated for each patient. TE $=$ score reduction/baseline score. A positive TE means amelioration, $T E=0$ unchanged, and a negative TE means worse. The primary aim was to calculate the TE's for RSA at 6, 12, 24, and 60 months postoperatively. The secondary aim was to analyze the influence of confounders (preoperative Hamada grade, age, gender, dominance, side of the affected shoulder, general co-morbidities measured using ASA grade).

Results: Two hundred three patients were included for this analysis of whom 183 patients had a complete 2 year follow up. Two years postoperatively the mean ASES score augmented significant from 20.5 to $78.7(p<0.001)$. The 2 year TE's ranged from 1 to 0.09 . We had no patient with a negative TE. A higher Hamada grade was associated with better TE's (Hamada grade 4+ vs. 2, $p$-value 0.042). For age and dominant side there were weak associations where those aged 80+ and dominant side had better TE's. The patients with higher ASA grade had lower TE's (ASA grade 4+ vs. 1, $p$-value 0.013). The mean TE's were 0.77 at 6 -months, 0.81 at 1 year, 0.76 at 2 years and 0.73 at 5 years.

Conclusions: The outcome for reverse shoulder arthroplasty can be measured with the treatment effect method; the 2 years TE's vary from 1 to 0.09 . The mean treatment effects change little in the first five postoperative years (from 0.73 to 0.81). The confounders for better TE's were: higher severity of cuff arthropathy (Hamada grade 3, 4 and 5), less comorbidities (ASA Grade 1), higher age (80+) and dominant side. Gender did not influence the 2-year TE's.
\end{abstract}

Trial registration: Comité intercantonal d'éthique (Jura, Fribourg, Neuchâtel), number 01/2008, 24.09.2008.

Keywords: Cuff arthropathy, Reverse shoulder arthroplasty, Treatment effect, Outcome, Confounders

\footnotetext{
* Correspondence: joerg.huber2@triemli.zuerich.ch

'Department of Orthopedics, Stadtspital Triemli, Birmensdorferstr. 497, 8063

Zurich, $\mathrm{CH}$, Switzerland

Full list of author information is available at the end of the article
}

(c) The Author(s). 2020 Open Access This article is licensed under a Creative Commons Attribution 4.0 International License, which permits use, sharing, adaptation, distribution and reproduction in any medium or format, as long as you give appropriate credit to the original author(s) and the source, provide a link to the Creative Commons licence, and indicate if changes were made. The images or other third party material in this article are included in the article's Creative Commons licence, unless indicated otherwise in a credit line to the material. If material is not included in the article's Creative Commons licence and your intended use is not permitted by statutory regulation or exceeds the permitted use, you will need to obtain permission directly from the copyright holder. To view a copy of this licence, visit http://creativecommons.org/licenses/by/4.0/. The Creative Commons Public Domain Dedication waiver (http://creativecommons.org/publicdomain/zero/1.0/) applies to the data made available in this article, unless otherwise stated in a credit line to the data. 


\section{Background}

Although shoulder arthroplasty is less common than knee or hip arthroplasty (in 2015 there were 83,886 primary hip arthroplasties, 94,023 primary knee arthroplasties, compared to 5221 primary shoulder arthroplasties in the UK NJR) [1] the outcome seems to be just as successful or even better in reducing pain and ameliorating shoulder function [2-7] compared to other total joint arthroplasties. From 1991 to 2010 the number of shoulder arthroplasties increased very rapidly with $98 \%$ for shoulder hemiarthroplasty and 393\% especially for reverse total shoulder arthroplasty (RSA) in the New York State [8]. In California, a similar trend was found with the incidence for shoulder arthroplasties rising from $6.1 / 100^{\prime} 000$ insured persons to $13.4 / 100^{\prime} 000$ persons in a large cohort of an integrated healthcare system [9].

Reverse total shoulder arthroplasty (RSA) is a biomechanical unique concept of replacement surgery in the shoulder successfully used in elderly patients with cuff tear arthropathy [10]. The underlying concept was to reverse the "ball and socket" principle of the shoulder joint to lengthen the lever arm for the deltoid muscle and the rotator cuff [10] and was first described 1994 by Grammont [11]. The type of prosthesis used in this study (Affinis ${ }^{\circledR}$ inverse, Fa Mathys, Bettlach, Switzerland) was developed and introduced to the market in 2007. It has been clinically and radiographically tested [12] and can be followed in the implant registries of the Netherlands, UK, AUS and NZ. The outcomes of RSA is promising and the good mid-term results are documented in different studies $[6,7,13-16]$. The long-term outcomes ( $>10$ years) showed a deterioration of clinical results compared to mid-term results and a prosthesis survivorship of 93\% [17].

The treatment effect (TE) is a simple method to calculate the outcome for every patient individually; $\mathrm{TE}=$ score reduction/baseline score (see Fig. 1). The TE measures the amount of amelioration for a treatment. A positive $\mathrm{TE}$ corresponds to an amelioration, $\mathrm{a} \mathrm{TE}=0$ to an unchanged situation and a negative TE to a worsening. The highest TE is 1 and corresponds to a patient without complaints after intervention [18, 19]. This kind of outcome analysis is not possible with "classical outcome" which compares the mean scores before and after treatment for a cohort. The TE method describes the variable outcome of each patient, enables closer analysis of outcome and of confounders. The method has been applied to measure outcomes of total hip/knee arthroplasty, but not yet to shoulder arthroplasty [18].

The primary aim of this study was to measure the TE's for RSA 6, 12, 24 and 60 months postoperatively. The secondary aim was to analyze the influence of confounders (Hamada grade of cuff arthropathy, age, gender, dominant side, ASA grade) on the outcome.

\section{Methods}

The European shoulder study group consists of five clinics specialized in shoulder surgery in three different countries (three clinics in Germany, two in France and one in Switzerland). Each clinic included their first consecutive patients in this open multicenter study. Included were patients with unilateral cuff arthropathy Hamada grade $>=2$ [20] who agreed to the informed consent approved by the local ethical committee. Excluded were the patients with trauma/fracture, secondary osteoarthritis, no informed consent, with rheumatoid arthritis, neoplasia, with incomplete data and who had a revision (change of basic parts of the implants) in the first 2 years.

Each patient had a primary assessment before surgery with PROM's (patient reported outcome measurements) in paper form and a clinical/functional examination to calculate the ASES score (American shoulder and elbow surgeons score [20]) and Constant score respectively [21]. In addition, the following information were collected: sociodemographic information (gender, age),

\section{$\mathrm{TE}=$ preoperative score - postoperative score \\ preoperative score}

Only with a positive score: $0=$ no complaints

Example 1: pretreatment score 98, post-treatment score 5;

$\mathrm{TE}=98-5 / 98=93 / 98=0.95$

Example 2: pretreatment score 55, post-treatment score 36;

$\mathrm{TE}=55-36 / 55=19 / 55=0.35$

Example 3: pretreatment score 80, post-treatment score 90;

$\mathrm{TE}=80-90 / 80=-10 / 80=-0.125$

Fig. 1 Calculating treatment effects: 3 examples 
dominance, side of the affected shoulder, and American Society of Anesthesiologists (ASA) grades as score for general comorbidities. The ASA definitions were: ASA 1 normal healthy person, ASA 2 patient with mild systemic disease, ASA 3 patient with severe systemic diseases, and ASA 4 patient with severe systemic diseases that is a constant threat to life [22]. Every patient had preoperative radiological assessment with standardized $\mathrm{x}$-rays (shoulder ap/scapula tangential) and MRI or CT-Scan to evaluate the Hamada grade of cuff arthropathy [20].

Each patient had reversed total shoulder arthroplasty (Affinis ${ }^{\circ}$ inverse, Fa Mathys, Bettlach, Switzerland) in a standardized way in beach chair position with cementless fixation of the base plate of the glenoid component and non-cemented or cemented fixation of the stem. The postoperative treatment with immobilization, physical therapy and beginning of loadbearing of the arm was individual and defined by each participating clinic.

Each patient had at least one complete follow up within 2 years with identical PROM's to calculate ASES score and a clinical examination for the Constant Score. If possible the identical PROM's were also collected 5 years after surgery. All data were documented separately in a central register. The ASES Score was used for the outcome as described in the original publication (50\% pain, $50 \%$ activities of daily living (ADL)), but for correct calculation of the treatment effect the ASES score was normalized to a score from 0 (best) to 100 (worst). The ASES has just two domains of pain and ADL, and hence was preferred to the Constant Score for the analysis, as this has too many dimensions (symptoms, ROM, force, ability to work).

\section{Statistical methods}

The outcome is measured as treatment effects (TE $=$ (preoperative score - postoperative score) / preoperative score). The calculations were performed for each patient at each follow up $(6,12,24$ and 60 months). The ASES Score had to be inversed ( $0=$ best, $100=$ worse) to allow us to calculate correctly the TE's. The confounders of interest were: Hamada grade of cuff arthropathy, age, gender, dominance, side of the affected shoulder, general comorbidities measured using ASA grades.

Descriptive statistics (mean, standard deviation for continuous variables and number, percentage for categorical) are used to exclude a selection bias by the patients that had a baseline assessment and no follow up.

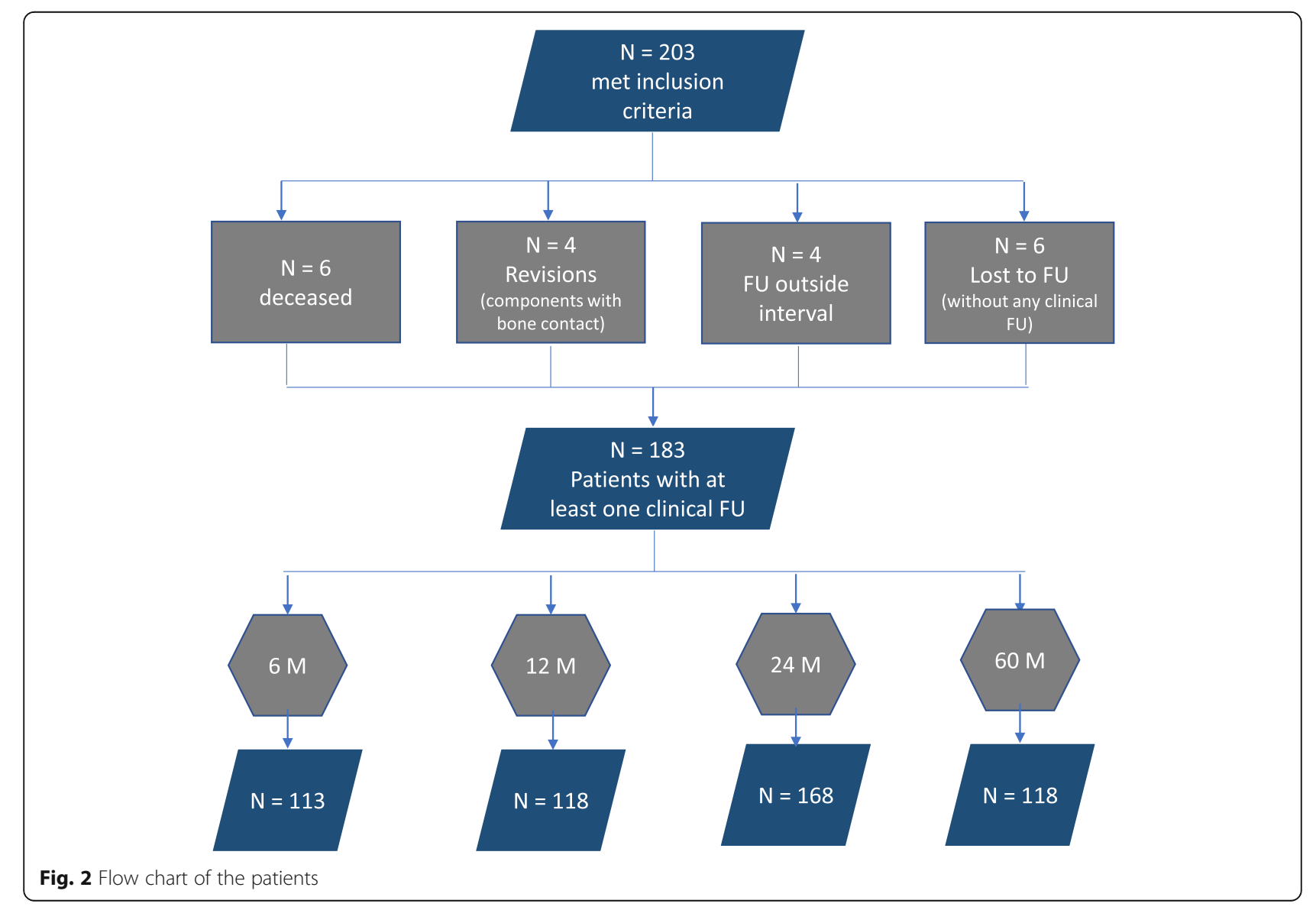


Box-whisker plots describe change in ASES and Constant scores over pre-operative and follow up time points. Kernel density plots describe the distribution of TE's over different follow ups. Linear regression modeling was used to describe the association of the confounders of interest.

\section{Results}

The study included 203 patients. Twenty had to be excluded (six for death not related to treatment, four for surgical revision of large parts with a good result in the further follow ups, and ten who were lost to follow up with a baseline assessment) (Fig. 2). This gave 183 patients with at least one clinical follow up in the first 5 years postoperatively, of whom 168 had a complete 2-year follow up ASES score (173 for the Constant Score) and 118 a complete 5-year follow up ASES score. The baseline pain, ASES and Constant scores of all included and excluded patients did not differ significantly (Table 1).

By 2 years, the mean ASES score augmented from 20.5 to 78.7 (a difference of 58.2 95\% CI (55.3 to 61.1), $p<0.001$ )
(Fig. 3a), and the Constant score from 25.4 to 67.8 (a difference of $42.495 \%$ CI (39.9 to 44.9), $p<0.001$ ) (Fig. 3b).

The TE's ranged from the maximum 1 to 0.09 for the 2-years follow up. We had no patient with a negative score. The median 2-years TE was 0.76 95\%CI (0.73, 0.79) (see Fig. 4). Comparing different follow-up intervals we found only small differences between the distributions of the mean TE's at 6 months, 1, 2 and 5-years (See Fig. 5), being 0.77, 0.81, 0.76 and 0.73 respectively.

There was some evidence of an association of Hamada grade on 2-year outcomes. The patients with a cuff tear arthropathy Hamada grade 4 and 5 had a mean TE that was 0.8 points higher compared to grade 2 as reference $(p=0.042)$ (Table 2).

The TE's differed weakly according to confounding factors of age, and dominant side but not for gender (Fig. 6). There was some difference by ASA grade whereby those with higher ASA grade had reduced TE's (median TE in ASA 1 was 0.85 versus 0.67 in ASA grade 4 ). This was confirmed by the adjusted linear regression analysis (ASA grade 4+ vs. 1 difference in

Table 1 Baseline characteristics of the patients at baseline and with at least one clinical follow up over 2 years

\begin{tabular}{|c|c|c|}
\hline & All Patients with pre-op data & Patients with follow up data \\
\hline & $N=203$ & $N=183$ \\
\hline \multicolumn{3}{|l|}{ Hamada Grade } \\
\hline Stage 2 & $55(27.1 \%)$ & 49 (26.8\%) \\
\hline Stage 3 & $43(21.2 \%)$ & $41(22.4 \%)$ \\
\hline Stage 4a; Stage 4b; Stage 5 & $105(51.7 \%)$ & 93 (50.8\%) \\
\hline \multicolumn{3}{|l|}{ Age } \\
\hline Mean (SD) & $74.9(6.7)$ & $74.7(6.5)$ \\
\hline Range & 41.9 to 91.6 & 41.9 to 87.5 \\
\hline \multicolumn{3}{|l|}{ Gender } \\
\hline Female & $134(66.0 \%)$ & $122(66.7 \%)$ \\
\hline Male & 69 (34.0\%) & $61(33.3 \%)$ \\
\hline \multicolumn{3}{|l|}{ Dominance } \\
\hline Dominant & $185(91.1 \%)$ & $166(90.7 \%)$ \\
\hline Non dominant & $18(8.9 \%)$ & $17(9.3 \%)$ \\
\hline \multicolumn{3}{|l|}{ ASA grade } \\
\hline 1 & $15(7.4 \%)$ & $13(7.1 \%)$ \\
\hline 2 & $22(10.8 \%)$ & $20(10.9 \%)$ \\
\hline 3 & 69 (34.0\%) & $66(36.1 \%)$ \\
\hline 4 and 5 & $97(47.8 \%)$ & 84 (45.9\%) \\
\hline \multicolumn{3}{|l|}{ ASES } \\
\hline Mean (SD) & $20.3(12.9)$ & $20.8(12.8)$ \\
\hline Range & 0.0 to 63.3 & 0.0 to 63.3 \\
\hline \multicolumn{3}{|l|}{ Constant } \\
\hline Mean (SD) & $24.6(13.2)$ & $25.3(13.2)$ \\
\hline Range & 3.0 to 67.0 & 3.0 to 67.0 \\
\hline
\end{tabular}



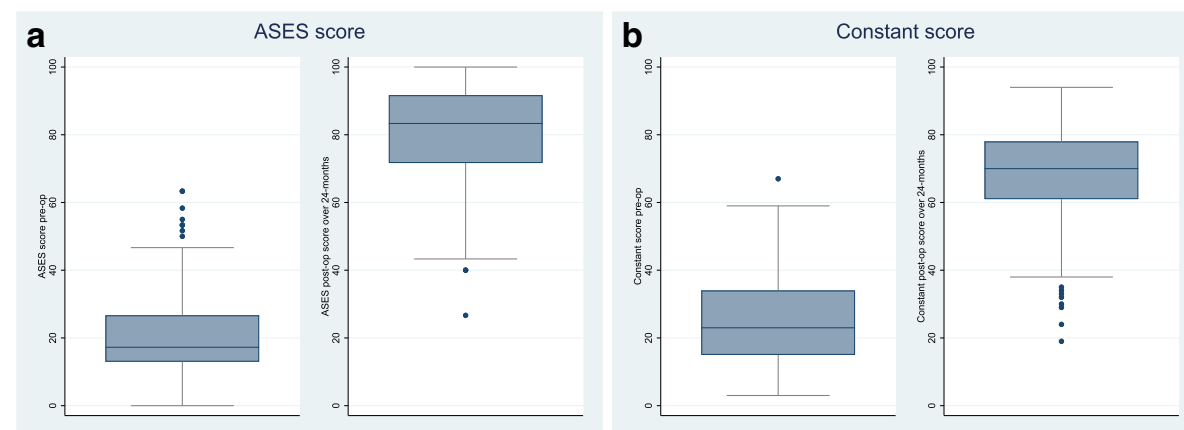

Fig. 3 Boxplot diagrams showing change of median score for ASES score, and Constant score pre-operatively and over two-year follow up

mean TE's -0.16 95\% confidence interval (CI) (- 0.03 to -0.28$), p$-value 0.013$)$. These findings agree with the few existing literature for total hip arthroplasty where a higher ASA grade correlates with lower TE's and age, gender have no influence [23].

\section{Discussion}

In this study the TE's of reverse shoulder arthroplasty were calculated for the first time using a standard score (ASES). The high treatment effects found correspond to the clinical success of RSA in patients with cuff arthropathy; mostly all patients had pain reduction and better function after surgery. The good results of earlier studies using the t-test were similar in this study (ASES Score from 20.5 to $78.7, p<0.001$ ).
The distribution of TE's as kernel density plots demonstrate that the ameliorations can be seen already 6 months after RSA and change little in the further follow-up to 5 years (range 0.73 to 0.81 in median TE's).

The most important factors influencing the outcome of the examined parameters were: the severity of cuff arthropathy as measured by Hamada grade, the grade of general comorbidities measured in ASA grades, age, and dominant side [22]. Interestingly there was no influence of gender.

This study is valuable because it's a multicenter study with a defined pathology and a single treatment; most other studies have mixed indications (e.g. fracture, revision) $[10,17]$. There are few multicenter studies about this type of arthroplasty with such a long follow up. Further, the data were collected in a standardized way.

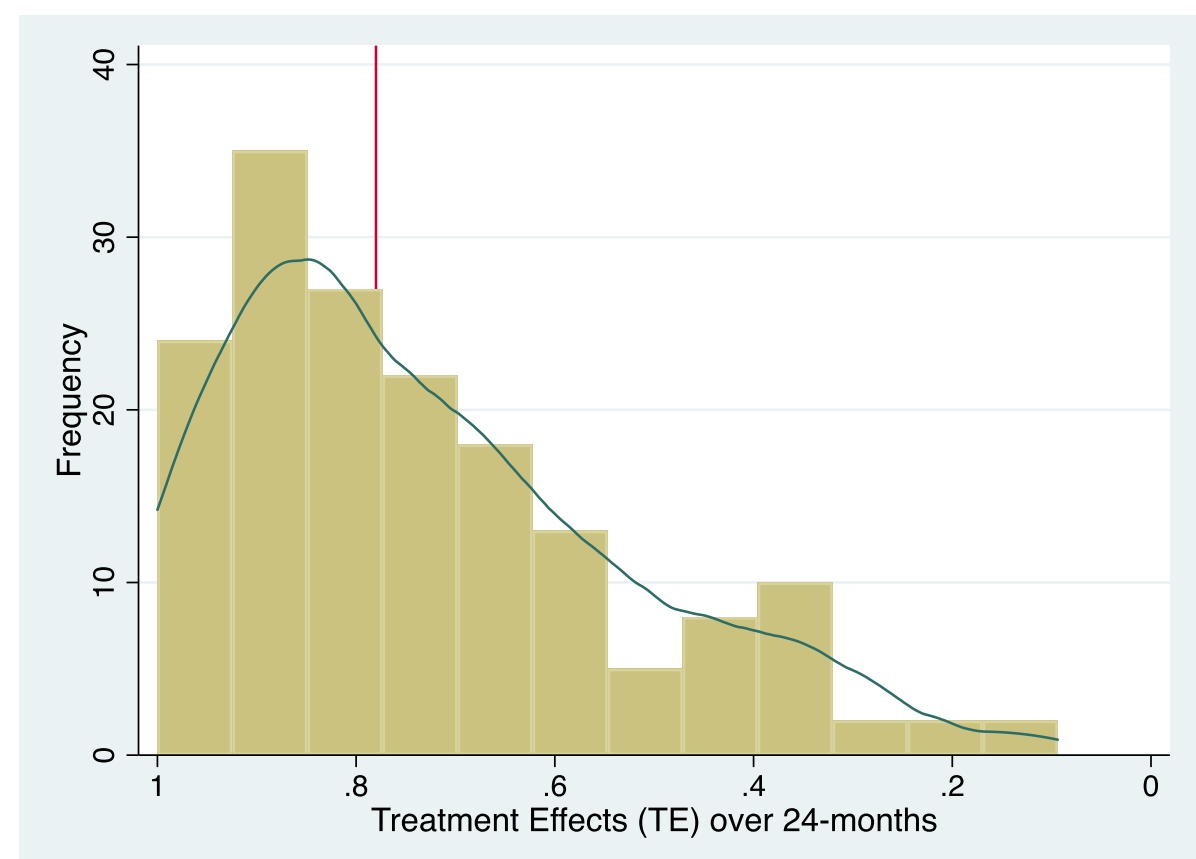

Fig. 4 Distribution of the treatment effects (TE's) for the two-year follow up 


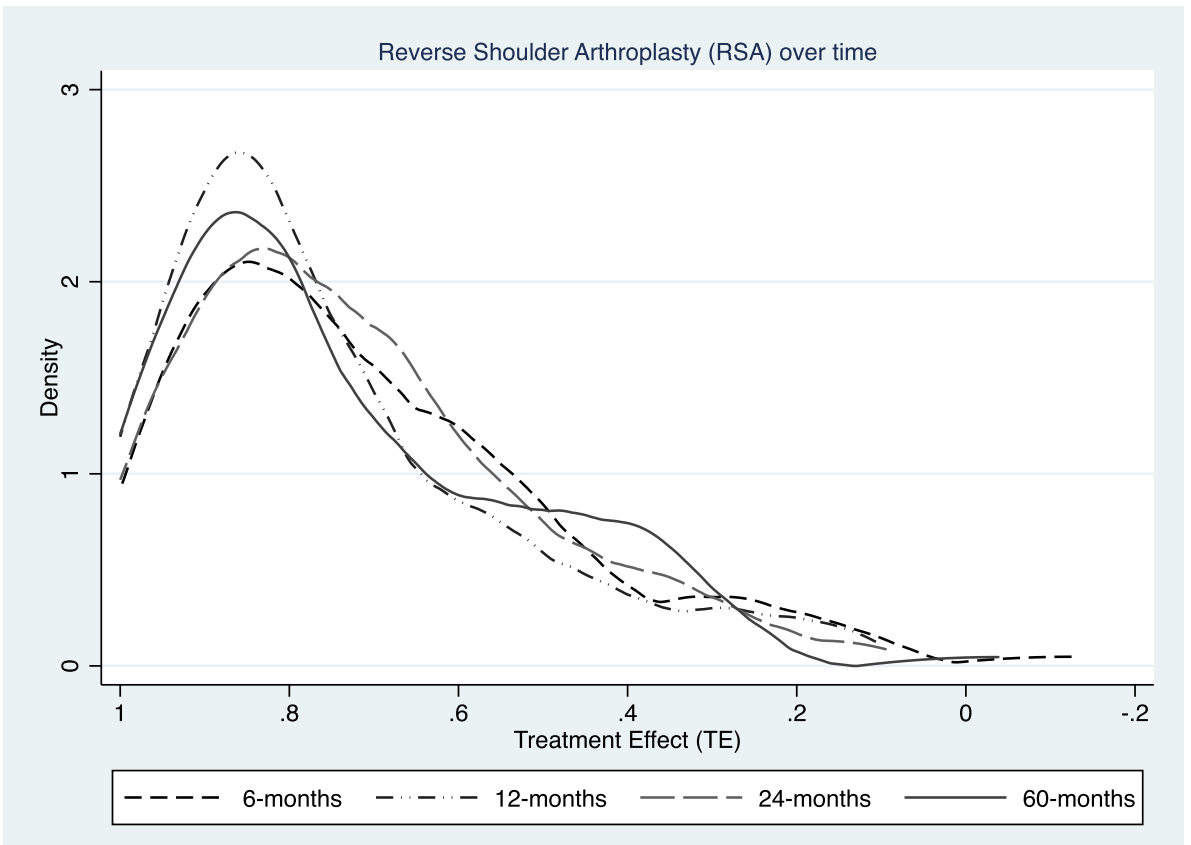

Fig. 5 Kernel density plots of distribution of TE's for 6, 12, 24 and 60 months follow up

Table 2 Results of linear regression model describing association of Hamada grade on TE's

\begin{tabular}{|c|c|c|c|c|}
\hline & Univariable & & Multivariable & \\
\hline & TE's over 24-months & & TE's over 24-months & \\
\hline & $\boldsymbol{N}=168$ & & $\boldsymbol{N}=168$ & \\
\hline & Coef $(95 \% \mathrm{Cl})$ & $\boldsymbol{P}$-value & Coef $(95 \%$ Cl) & $\boldsymbol{P}$-value \\
\hline \multicolumn{5}{|l|}{ Main Predictor } \\
\hline \multicolumn{5}{|l|}{ Hamada Grade } \\
\hline Stage 2 & REF & & REF & \\
\hline Stage 3 & $0.06(-0.03,0.14)$ & 0.194 & $0.05(-0.03,0.14)$ & 0.229 \\
\hline Stage 4a; Stage 4b; Stage 5 & $0.07(-0.01,0.14)$ & 0.07 & $0.08(0.00,0.15)$ & 0.042 \\
\hline \multicolumn{5}{|l|}{ Confounders } \\
\hline \multicolumn{5}{|l|}{ Age } \\
\hline$<70$ & REF & & REF & \\
\hline 70 to 80 & $0.01(-0.07,0.08)$ & 0.894 & $0.02(-0.05,0.10)$ & 0.546 \\
\hline $80+$ & $0.07(-0.03,0.17)$ & 0.177 & $0.09(-0.01,0.20)$ & 0.087 \\
\hline \multicolumn{5}{|l|}{ Gender } \\
\hline Female & REF & & REF & \\
\hline Male & $-0.02(-0.08,0.05)$ & 0.604 & $-0.02(-0.09,0.04)$ & 0.518 \\
\hline \multicolumn{5}{|l|}{ Dominant side } \\
\hline Dominant & REF & & REF & \\
\hline Non-dominant & $-0.07(-0.17,0.04)$ & 0.213 & $-0.10(-0.21,0.01)$ & 0.07 \\
\hline \multicolumn{5}{|l|}{ ASA grade } \\
\hline 1 & REF & & REF & \\
\hline 2 & $-0.03(-0.17,0.11)$ & 0.673 & $-0.02(-0.16,0.12)$ & 0.79 \\
\hline 3 & $-0.07(-0.19,0.06)$ & 0.28 & $-0.09(-0.21,0.03)$ & 0.157 \\
\hline 4 and 5 & $-0.11(-0.24,0.01)$ & 0.065 & $-0.16(-0.28,-0.03)$ & 0.013 \\
\hline
\end{tabular}



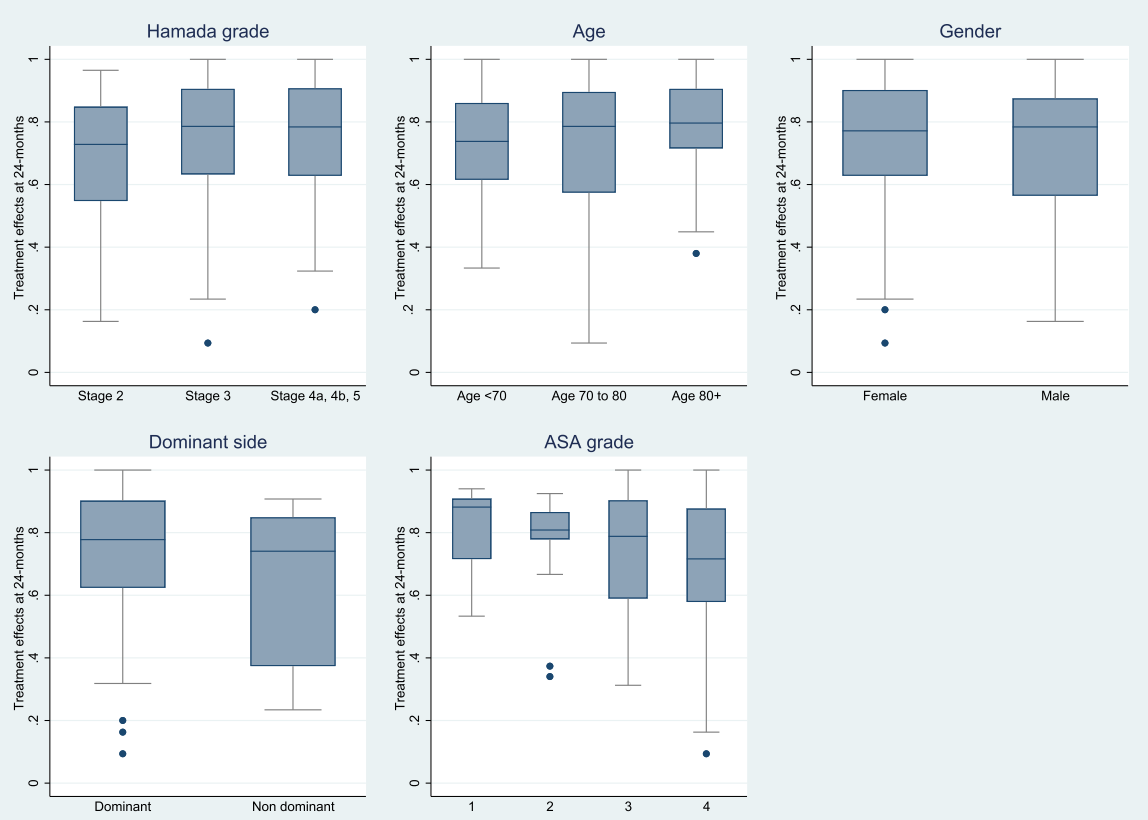

Fig. 6 Box-plot of TE's for main predictor (Hamada grade) and confounders (gender, age, dominance, comorbidities as ASA Score)

The limitations of this study were: 1 the results cannot be directly compared to other shoulder studies because in this study the TE method was applied the first time to measure outcome of RSA. 2 The open design of the study with at least one follow up lead to a slightly reduced number of patients with a 2 years follow up. $3 \mathrm{~A}$ bias factor would be the interest and expertise of each participant surgeon in shoulder surgery and in careful patient selection to get good results. That might be a reason to explain that there was no patient with a negative TE. Existing studies also have more homogeneous populations, being single center studies, with only a single follow up time point that is not consistent between patients.

\section{Conclusion}

The outcome for RSA in patients with cuff arthropathy can be measured with TE's using the inverted ASES score. The excellent results also in this study may explain the fast success and rapidly increasing numbers of this treatment. The results can be seen already early 6 months after RSA with only small changes over a longer follow interval up to 5 years.

\section{Abbreviations}

RSA: reversed total shoulder arthroplasty; ASES: American Society of Shoulder and Elbow Surgeons Score; TE: Treatment effect; ASA: American Society of Anesthesiologists Score; UK: United Kingdom; NJR: National joint registry (UK); AUS: Australia; NZ: New Zealand; PROM's: Patient reported outcome measurements; MRI: Magnetic resonance imaging; CT: Computer tomography; ADL: Activity of daily living; ROM: Range of motion; $\mathrm{Cl}$ : Confidence interval

\section{Acknowledgments}

We wanted to thank Dr. Thierry Joudet, Clinique du Libournais, F 33500 Libourne (France) for his support of this study with his serie of consecutive of patients and the data collection in the follow-up period.

\section{Authors' contributions}

$\mathrm{JH}$ and AJ designed the study. The surgeries were performed by UI, MK, FR, GK and TJ. The data were collected in each clinic by UI, MK, FR, GK and TJ. $\mathrm{JH}$ and $\mathrm{AJ}$ analyzed the data and prepared the manuscript with tables and Figures. UI, MK, FR, GK revised the manuscript critically. All authors read an approval of the final manuscript.

\section{Funding}

No funding.

\section{Availability of data and materials}

Anonymized source data can be obtained from the corresponding author on reasonable request.

\section{Ethics approval and consent to participate}

The study was approved by the regional ethics committee (Comité intercantonal d'éthique (Jura, Fribourg, Neuchâtel), number 01/2008, 24.09.2008. Written informed consent was obtained from all individual patients included in the study at each hospital site.

\section{Consent for publication}

Not applicable.

\section{Competing interests}

The authors declare, that they have no competing interests.

\section{Author details}

${ }^{1}$ Department of Orthopedics, Stadtspital Triemli, Birmensdorferstr. 497, 8063 Zurich, $\mathrm{CH}$, Switzerland. ${ }^{2}$ Orthopedic Clinics, Marienstift, Wachsenburgallee 12, D 99310 Arnstadt, Germany. ${ }^{3}$ Sportorthopädicum Straubing, Bahnhofplatz 27, D 94315 Straubing, Germany. ${ }^{4}$ DRK Kliniken Köpenick,

Salvador-Allende-Strasse 2-8, D 12559 Berlin, Germany. ${ }^{5}$ Clinique generale, Rue Hans Geiler 6, 1700 Fribourg, CH, Switzerland. ${ }^{6}$ Musculoskeletal Research Unit, Translational Health Sciences, Bristol Medical School, University of 
Bristol, Learning \& Research Building, Southmead Hospital, Bristol BS10 5NB, UK. 'Nuffield Department of Orthopedics, Rheumatology and Musculoskeletal Sciences, University of Oxford, Windmill Road, Headington OX3 7LD, UK. ${ }^{8}$ MRC Lifecourse Epidemiology Unit, Southampton General Hospital, University of Southampton, Southampton SO16 6YD, UK.

Received: 5 March 2020 Accepted: 16 June 2020

Published online: 22 June 2020

\section{References}

1. National Joint Registry, National Joint Registry for England, Wales, Northern Ireland and the Isle of Man. 13th Annual Report. 2016. https://reports.njicentre. org.uk.

2. Wiater JM, et al. Clinical and radiographic results of cementless reverse total shoulder arthroplasty: a comparative study with 2 to 5 years of follow-up. J Shoulder Elb Surg. 2014;23(8):1208-14.

3. Kiet TK, et al. Outcomes after shoulder replacement: comparison between reverse and anatomic total shoulder arthroplasty. J Shoulder Elb Surg. 2015;24(2):179-85.

4. Ballas R, Teissier P, Teissier J. Stemless shoulder prosthesis for treatment of proximal humeral malunion does not require tuberosity osteotomy. Int Orthop. 2016;40(7):1473-9.

5. Young AA, et al. Early results of reverse shoulder Arthroplasty in patients with rheumatoid arthritis. JBJS. 2011;93(20):1915-23.

6. Wall B, et al. Reverse total shoulder arthroplasty: a review of results according to etiology. J Bone Joint Surg Am. 2007;89(7):1476-85.

7. Frankle $\mathrm{M}$, et al. The reverse shoulder prosthesis for glenohumeral arthritis associated with severe rotator cuff deficiency. A minimum two-year followup study of sixty patients. J Bone Joint Surg Am. 2005;87(8):1697-705.

8. Khatib O, et al. Shoulder arthroplasty in New York state, 1991 to 2010: changing patterns of utilization. J Shoulder Elb Surg. 2015;24(10):e286-91.

9. Dillon, M.T., et al., Yearly Trends in Elective Shoulder Arthroplasty, 2005 through 2013. Arthritis Care Res 2016: p. n/a-n/a.

10. Nam D, et al. Rotator cuff tear arthropathy: evaluation, diagnosis, and treatment: AAOS exhibit selection. J Bone Joint Surg Am. 2012;94(6):e34.

11. Flatow EL, Harrison AK. A history of reverse Total shoulder Arthroplasty. Clin Orthop Relat Res. 2011;469(9):2432-9.

12. Irlenbusch U, et al. Reversed shoulder arthroplasty with inversed bearing materials: 2-year clinical and radiographic results in 101 patients. Arch Orthop Trauma Surg. 2015;135(2):161-9.

13. Baulot E, Sirveaux F, Boileau P. Grammont's idea: the story of Paul Grammont's functional surgery concept and the development of the reverse principle. Clin Orthop Relat Res. 2011:469(9):2425-31.

14. Bohsali KI, Wirth MA, Rockwood CA Jr. Complications of total shoulder arthroplasty. J Bone Joint Surg Am. 2006;88(10):2279-92.

15. Boileau P. Complications and revision of reverse total shoulder arthroplasty. Orthop Traumatol Surg Res. 2016;102(1 Suppl):S33-43.

16. Gerber C, Pennington SD, Nyffeler RW. Reverse total shoulder arthroplasty. J Am Acad Orthop Surg. 2009;17(5):284-95.

17. Bacle G, et al. Long-term outcomes of reverse Total shoulder Arthroplasty: a follow-up of a previous study. J Bone Joint Surg Am. 2017;99(6):454-61.

18. Huber J, et al. Relative effect per patient (REPP)--outcome groups for total hip replacement and total knee replacement. Z Orthop Unfall. 2013:151(3):239-42.

19. Huber J, et al. A new responder criterion (relative effect per patient (REPP) > $0.2)$ externally validated in a large total hip replacement multicenter cohort (EUROHIP). Osteoarthr Cartil. 2016;24(3):480-3.

20. Walch G, et al. Arthroscopic tenotomy of the long head of the biceps in the treatment of rotator cuff tears: clinical and radiographic results of 307 cases. J Shoulder Elb Surg. 2005;14(3):238-46.

21. Constant CR, Murley AH. A clinical method of functional assessment of the shoulder. Clin Orthop Relat Res. 1987;214:160-4.

22. Saklad MDM. Grading of patients for surgical procedures. Anesthesiology. 1941;2(3):281-4.

23. Huber J, et al. The influence of arthritis in other major joints and the spine on the one-year outcome of Total Hipf replacement. J Bone Joint Surg Am. 2017;99(p):1428-37.

\section{Publisher's Note}

Springer Nature remains neutral with regard to jurisdictional claims in published maps and institutional affiliations.

Ready to submit your research? Choose BMC and benefit from:

- fast, convenient online submission

- thorough peer review by experienced researchers in your field

- rapid publication on acceptance

- support for research data, including large and complex data types

- gold Open Access which fosters wider collaboration and increased citations

- maximum visibility for your research: over $100 \mathrm{M}$ website views per year

At BMC, research is always in progress.

Learn more biomedcentral.com/submissions 